\title{
EFEKTIVITAS PENGGUNAAN BAHAN KOAGULAN DALAM PROSES PERENCANAAN PENGOLAHAN BANGUNAN AIR MINUM
}

\author{
Septyn Anggun Lestari \\ Jurusan Teknik Lingkungan, Fakultas Arsitektur Lanskap dan Teknologi Lingkungan, \\ Universitas Trisakti, Jakarta, Indonesia \\ Email korespondensi: septyn08215054@std.trisakti.ac.id
}

\begin{abstract}
ABSTRAK
Pengolahan air minum diperlukan untuk menghasilkan air minum yang sesuai dengan Permenkes RI No. 492 Tahun 2010 Tentang Persyaratan Kualitas Air Minum agar dapat dikonsumsi oleh masyarakat. Instalasi Pengolahan Air Minum terdiri dari beberapa unit seperti intake, koagulasi, flokulasi, sedimentasi, filtrasi dan desinfeksi. Salah satu proses utama dala Instalasi Pengolahan Air Minum adalah proses koagulasi yang berfungsi untuk mengikat partikel - partikel di dalam air dengan menambahkan koagulan. Pemberian dosis koagulan yang tidak tepat dapat merusak kualitas air. Metode yang digunakan untuk mencari dosis optimum minimum adalah jartest. Proses koagulasi bisa terhambat jika tingkat kekeruhan terlalu rendah atau terlalu tinggi. Untuk itu perlu ditentukan dosis optimum pemakaian koagulan pada kondisi kekeruhan air baku yang berbeda. Salah satu bahan koagulan yang dapat digunakan dalam poses penjernihan air adalah Pollyaluminium Chloride (PAC) dan Alumnium Sulfat. Kedua bahan koagulan ini paling banyak dipakai dan mudah diperolah di pasar. Kisaran $\mathrm{pH}$ dengan koagulan Aluminium Sulfat berkisar antara 5,5-7,5. Tujuan karya ilmiah ini adalah untuk mendapatkan jenis dan dosis koagulan yang tepat dalam proses pengolahan air baku menjadi air minum. Karya ilmiah ini diharapkan dapat memberikan informasi ilmiah tentang penggunaan jenis koagulan yang efektif dan efisien dalam memperbaiki kualitas air baku.
\end{abstract}

Kata Kunci: Koagulan, dosis optimum, Pollyaluminium Chloride, Aluminium Sulfat

\section{PENDAHULUAN}

Dalam merencanakan Bangunan Pengolahan Air Minum diperlukan beberapa unit instalasi seperti intake, koagulasi, flokulasi, sedimentasi, filtrasi, desinfeksi dan reservoir. Salah satu faktor yang dapat mempengaruhi pemilihan unit pengolahan adalah karakteristik air baku dengan parameter yang tidak memenuhi baku mutu. Penentuan unit pengolahan dilakukan dengan studi literature dan \% penyisihan pada tiap unit di setiap parameter yang tidak memenuhi baku mutu. Salah satu unit pengolahan yang dapat meningkatkan \% penyisihan adalah unit koagulasi. Karya Ilmiah ini membahas berbagai jenis bahan koagulan yang dapat digunakan dalam proses penjernihan air pada Instalasi Pengolahan Air Minum (IPAM) Untuk menentukan dosis optimum koagulan metode yang digunakan adalah analisis jartest. Berdasarkan uraian tersebut karya ilmiah ini bertujuan untuk memperoleh jenis dan dosis koagulan yang tepat dan efisien dalam proses pengolahan air baku menjadi air minum.

\section{TINJAUAN PUSTAKA}

Secara garis besar satuan operasi dalam proses pengolahan air yang biasa dipergunakan adalah intake, koagulasi, flokulasi, sedimentasi, filtrasi, dan desinfeksi. Menurut Smaradhana, (2016) Dalam merencanakan Bangunan Pengolahan Air Minum diperlukan pemilihan alternatif pengolahan untuk mengoptimalkan unit pengolahan sehingga menghasilkan air olahan yang berkualitas sesuai yang diinginkan. Unit koagulasi 
merupakan salah satu unit yang dapat mengoptimalkan pengolahan. Proses yang terjadi di dalam unit koagulasi memerlukan bahan kimia yang disebut koagulan. Koagulan berfungsi sebagai destabilisasi partikel dan penguatan flok untuk mengurangi pecahnya flok. Dalam penentuan koagulan dilakukan percobaan jartest. Berikut beberapa jenis bahan koagulan yang sering digunakan dalan proses pengolahan air minum :

\section{1) Pollyaluminium Chloride (PAC)}

Pollyaluminium Chloride (PAC) merupakan salah satu jenis koagulan yang sering digunakan. PAC tersedia dalam bentuk cair dan padat tergantung sesuai kebutuhan yang diinginkan dalam penjernihan air. PAC sering digunakan sebagai bahan koagulan untuk menggumpalkan partikel agar terbentuk flok sehingga dapat mengurangi tingkat kekeruhan air. PAC memiliki rumus umum kimia :

$$
\mathrm{Al}_{2}(\mathrm{OH})_{6-\mathrm{n}} \mathrm{Cl}_{\mathrm{n}} \times \mathrm{H}_{2} \mathrm{O}(\mathrm{n}=1-5)
$$

PAC dapat dibuat dengan mereaksikan Aluminium dengan Asam klorida ( $\mathrm{HCl}) 5-15 \%$ pada suhu $67-97^{\circ} \mathrm{C}$.

Berikut beberapa manfaat yang dapat diperoleh dari penggunaan PAC sebagai bahan koagulan :

1. PAC bebas dari Sulfat sehingga memili tingkat korosif yang rendah dan aman digunakan selain itu dalam penyimpanan dan transportasinya lebih mudah.

2. Penggunaan PAC tidak terlalu mempengaruhi perubahan $\mathrm{pH}$ yang signifikan dibandingkan bahan koagulan lainnya yang cenderung membentuk logam hidroksida

Pada proses penambahan koagulan akan terjadi gaya Van der Waals dimana kation akan menetralisasi muatan negatif partikel koloid dalam air sehingga terbentuk flok. Berdasarkan penelitian sebelumnya penambahan PAC dengan dosis 100 ppm,akan melepasakan kation lebih besar dibandingkan yang dibutuhkan oleh partikel koloid bermuatan negative di dalam air untuk membentuk flok. Akibatnya akan terjadi penyerapan kation yang berlebih oleh partikel koloid dalam air sehingga partikel koloid akan bermuatan positif dan terjadi deflokulasi flok. Defokulasi flok akan menyebabkan larutan menjadi semakin keruh dan nilai turbiditas air sungai menjadi meningkat.

Budiman (2010) menyatakan kadar PAC yang semakin tinggi berkisar dari $10-50$ ppm pada musim kemarau akan menghasilkan nilai kekeruhan menurun. Akan tetapi apabila kadar PAC semakin ditingkaktkan hingga $75-100$ ppm nilai kekeruhan akan meningkat, hal ini diakibatkan kerena penambhan koagulan yang berlebih dapat menyebabkan terjadinya deflokulasi sebagai akibat flok yang terbentuk pecah. Dari hasil penelitian pada musim hujan, dosisi optimum PAC yang dibutuhkan sebesar 75 ppm dimana dengan dosis tersebut dapat menurunkan nilai kekeruhan air yang lebih baik dibandingkan dengan menggunakan dosisi PAC $50 \mathrm{ppm}$. Hal ini disebabkan pada penambahan PAC dengan kadar 75 ppm untuk musim kemarau kurang cocok sehingga menyebabkan defokulasi flok.Berdasarkan percobaan tersebut maka dalam menentukan dosis optimum koagulan disesuaikan dengan kondisi kualitas air baku.

Menurut Andini, (2017) sungai dengan kekeruhan 6,53 NTU dapat menggunakan koagulan Polyaluminium Chloride (PAC) dengan dosis optimum $40 \mathrm{ppm}$. Nilai kekeruhan akan memengaruhi dosis optimum koagulan. Kadar PAC yang digunakan pada musim hujan sebesar 75 ppm dengan kecepatan pengadukan $100 \mathrm{rpm}$ menghasilkan nilai turbiditas air sungai menjadi 0,8 NTU.. Mayasari (2018) menyebutkan konsentrasi PAC optimum 25 ppm dengan efisiensi sebesar 63,9\%. Efisiensi penggunaan koagulan Aluminium sulfat dan PAC masing-masing memiliki efisiensi yang semakin tinggi setelah dilakukan penambahan konsentrasi koagulan. Efisiensi tertinggi koagulan PAC terdapat pada konsentrasi 120 ppm sebesar 69\% sedangkan Aluminium Sulfat pada konsentrasi 160 ppm sebesar $63,9 \%$. 


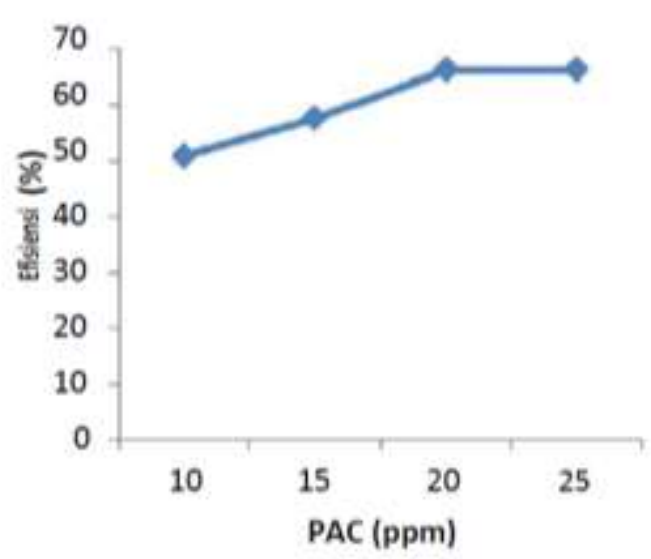

Gambar 1 Efisiensi penggunaan bahan koagulan PAC (Mayasari, 2018)

\section{2) Aluminium Sulfat $\left(\mathrm{Al}_{2} \mathrm{SO}_{4}\right)$}

Aluminium sulfat, merupakan senyawa kimia anorganik yang memiliki rumus $\mathrm{Al}_{2}\left(\mathrm{SO}_{4}\right)_{3}$. Aluminium sulfat memiliki sifat larut dalam air yang biasanya digunakan sebagai bahan koagulan dalam proses penjernihan air minum, kilang pengolahan air limbah, serta pembuatan kertas. Aluminium kalium sulfat biasanya ditemukan dalam ragi, Dalam industri konstruksi Aluminium sulfat dapat digunakan sebagai zat yang tahan air (waterproofing) dan akselerator pada beton..

$\mathrm{pH}$ merupakan salah satu faktor yang mempengaruhi bahan koagulan yang akan digunakan. Dimana bahan koagulan biasanya memiliki rentan $\mathrm{pH}$ yang berbeda-beda. Pada koagulan Aluminium sulfat atau yang sering disebut tawas memiliki kisaran $\mathrm{pH}$ antara 5,5 - 7,5. Berdasarkan penelitian yang telah dilakukan oleh Muhammad Ridwan dan James Nobelia L, semakin tinggi tingkat kekeruhan alkalinitas dan zat organik semakin tinggi juga dosis koagulan yang dibutuhkan untuk membentuk flok. Hal ini justru berbanding terbalik dengan $\mathrm{pH}$ yang memiliki hunbungan negatif dengan dosis koagulan. Pada Gambar 2 terlihat hubungan antara kekeruhan, $\mathrm{pH}$, dan dosis koagulan akan membentuk kurva berbentuk U (parabola terbuka). Dari gambar grafik tersebut dapat digunakan untuk melihat dosis minimal yang dapat dijadikan dosis yang paling cocok untuk plant.

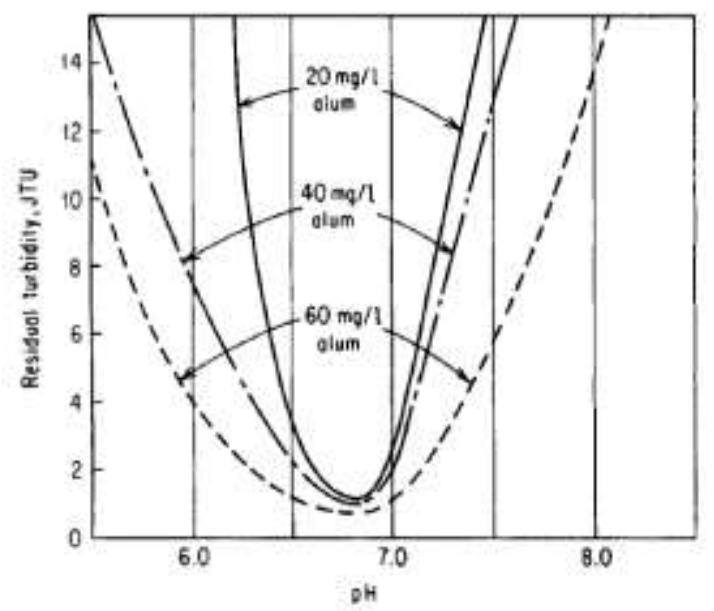

Gambar 2 Pengaruh Dosis Koagulan Aluminum Sulfat terhadap pH (Ayundyahrini,2013).

Penggunaan bahan koagulan Aluminium sulfat dapat melepaskan satu ion Hidrogen $\left(\left(\mathrm{H}^{+}\right)\right.$ pada tiap gugus Hidrogen yang telah dihasilkan. Ion hidrogen yang dihasilkan akan menyebabkan air hasil olahan menjadi asam dikarenakan penurunan $\mathrm{pH}$ yang cukup tinggi. 
Alum dengan dosis 200 ppm direkomendasikan untuk menjernihkan pengolahan air di Sumur Batu dengan kefektifan penurunan nilai BOD hingga 60,16\% (Madonna, 2019).

Tabel 1 Perbandingan Harga Bahan Koagulan Pollyaluminium Chloride dengan Aluminium Sulfat (Madonna, 2019)

\begin{tabular}{llccc}
\hline No & Nama Koagulan & Bentuk & Harga $(\mathrm{Rp})$ & Dosis $(\mathrm{mg} / \mathrm{L})$ \\
\hline 1. & Pollyaluminum Chloride $(\mathrm{PAC})$ & Bubuk & $4.500 / \mathrm{kg}$ & 200 \\
\hline 2. & Aluminium sulfat $\left(\mathrm{Al}_{2} \mathrm{SO}_{4}\right)$ & Bubuk & $3.000 / \mathrm{kg}$ & 200 \\
\hline
\end{tabular}

\section{Penentuan Dosis Optimum Koagulan dengan Alat Jartest}

Untuk mengetahui dosis optimum yang diperlukan dalam proses koagulasi dapat menggunakan metode Jartest. Dalam melakukan jartest hal yang perlu diperhatikan antara lain dosis optimum penambahan koagulan, lama pengendapan serta volume endapan yang terbentuk. Selain itu kecepatan dan lama waktu pengadukan akan mempengaruhi hasil jartest yang akan terlihat pada bentuk flok yang terbentuk dan tingkat kekeruhain air hasil percobaan jartest. Untuk menghasilkan data dosis optimum yang aktual, Jartest sebaiknya dilakukan setiap saat apabila keadaan air berubah baik perubahan musim ataupun faktor lain seperti kualitas air baku. Alat Jartest biasanya terdiri dari enam buah batang pengaduk dimana masing - masing mengaduk terdiri dari satu buah gelas dengan kapasitas satu liter. Satu buah gelas berfungsi sebagai kontrol dan lima gelas lainnya sebagai proses pengadukan dengan berbagai dosis koagulan sehingga dapat dibandingkan hasil percobaan jartest untuk menentukan dosis optimum koagulan.

\section{PENUTUP}

Jenis dan dosis optimum koagulan merupakan hal penting dalam merencanakan Instalasi Pengolahan Air Minum. Berdasarkan sumber literatur yang didapatkan penulis merokemendasikan bahan koagulan yang cukup efektif dan efisien adalah Aluminium sulfat $\left(\mathrm{Al}_{2} \mathrm{SO}_{4}\right)$. Penggunaan bahan koagulan Aluminium sulfat menghasilkan air yang lebih jernih dan harga Aluminium sulfat lebih murah dibandingkan PAC.

\section{DAFTAR PUSTAKA}

Crittenden, John C. 2012. MWH's Water Treatment: Principles and Design. John Wiley \& Sons, Inc. DOI : $10.1002 / 9781118131473$

Haq, Raidah Afifatul.2018. Perencanaan Unit Bangunan Pengolahan Air Bersih di Pondok Pesantren Baiturrahman Ciparay Bandung. Bandung : Institut Teknologi Bandung.

Howe, Kerry J et al. 2012. Principles of Water Treatment. John Wiley \& Sons, Inc.

Madonna, Sarra dkk. 2019. Laboratory Study On The Optimization Of IPLT Sumur Batu Dewatering Unit Using Different Coagulants. Indonesian Journal Of Urban and Environmental Technology. 2(2):134-145

DOI : $10.25105 /$ urbanenvirotech.v0i0.4365

Margareta, Rizka Mayasari, dkk. (2012).Pengaruh Kualitas Air Baku Terhadap Dosis Dan Biaya Koagulan Aluminium Sulfat Dan Poly Aluminium Chloride. Jurnal Teknik Kimia, No.4, Vol.18.

Mayasari, Rizka. Optimalisasi Dosis Koagulan Aluminium Sulfat dan Poli Aluminium Klorida (PAC) (Studi Kasus PDA Tirta Musi Palembang). Jurnal Universitas Muhammadiyah Palembang. 2(3): 2528-7419. 
Peraturan Menteri Kesahatan Republik Indonesia No. 416/MENKES/PER/IX/1990.

Priambodo, Eko Ary. 2017.Perancangan Unit Instalasi Pengolahan Air Minum Kamus Institus Teknologi Sepuluh November.. Jurnal Teknik ITS. 1(6): 2337-3539

Puspitasari, Mega. 2014. Efektifitas $\mathrm{Al}_{2}\left(\mathrm{SO}_{4}\right)_{3}$ dan $\mathrm{FeCl}_{3}$ Dalam Pengolahan Air. Menggunakan Gravel Bed Flocculator Ditinjau Dari Parameter Kekeruhan dan Total Coli. Jurnal Teknik POMITS. 2(3): 2337-3539

Smaradhana C, Samudro G, Nugraha WD. 2016. Perencanaan Teknis Instalasi Pengolahan Air Minum Pejaten Jakarta Selatan dengan Debit 200 Liter Per Detik. Jurnal Teknik Lingkungan Vol. 5, No. 4, 2.

Sarikusmayadi, Astri Aprilia. 2015. Teknologi Pengolahan Air Untuk Kondisi Darurat. Bandung : Institut Teknologi Bandung.

SNI 0004 - 2008 Tata Cara commissioning Instalasi Pengolahan Air

Yulistiyanto, Bambang dan Kironoto, BA. 2008. Analisa Pendayagunaan Sumberdaya Air Pada WS Paguyaman dengan RIBASIM. Media Teknik No 2 Tahun XXX Edisi Mei 2008 ISSN 0216-3012. 